\title{
Mouse RIC-3, an Endoplasmic Reticulum Chaperone, Promotes Assembly of the $\alpha 7$ Acetylcholine Receptor through a Cytoplasmic Coiled-Coil Domain
}

\author{
Ying Wang, ${ }^{1,2}$ Yun Yao, ${ }^{2}$ Xiao-Qing Tang, ${ }^{2}$ and Zuo-Zhong Wang ${ }^{1,2,3 \dagger}$ \\ ${ }^{1}$ Neuroscience Graduate Program, ${ }^{2}$ Zilkha Neurogenetic Institute, and ${ }^{3}$ Department of Cell and Neurobiology, University of Southern California Keck \\ School of Medicine, Los Angeles, California 90033
}

\begin{abstract}
RIC-3 (resistant to inhibitor of cholinesterase) is a transmembrane protein, found in invertebrates and vertebrates, that modulates the surface expression of a variety of nicotinic acetylcholine receptors (nAChRs) in neurons and other cells. To understand its mechanism of action, we investigated the cellular location, transmembrane topology and cellular mechanism by which RIC-3 facilitates $\alpha 7$ assembly and surface expression in cultured mammalian cells. We show that the mouse protein is targeted to the ER by the first 31 aa which act as a cleavable signal sequence. The mature protein is a single-pass type I transmembrane protein whose $\mathrm{N}$ terminus resides in the lumen of the ER with the coiled-coil domain in the cytoplasm. RIC-3, which binds both unfolded and folded $\alpha 7$ subunits, facilitates the surface expression of receptor principally by promoting the folding and assembly of the $\alpha 7$ subunits in the ER into fully polymerized receptor. Functional analysis shows that facilitation of surface expression of $\alpha 7$ in mammalian cells is reduced in RIC-3 mutants lacking the signal peptide, the lumenal segment or the coiled-coil domain, but not in mutants lacking the long C-terminal region downstream of the coiled-coil domain. We show that the coiled-coil domain of mRIC-3 is not required for the interaction of mRIC-3 with $\alpha 7$, but does mediate a homotypic interaction between molecules of mRIC-3. We suggest that efficient assembly of the homomeric $\alpha 7 \mathrm{nAChR}$ may thus require mRIC-3 self-association through the cytoplasmic coiled-coil domain and suggest a model by which this may occur.
\end{abstract}

\section{Introduction}

Nicotinic acetylcholine receptors (nAChRs) are pentameric transmembrane proteins that belong to a family of cys-loop ligandgated ion channels (Lester et al., 2004). The receptors are concentrated at synapses in muscle cells and in the peripheral nervous system and the CNS, where they mediate a variety of synaptic actions (McGehee and Role, 1995; McGehee, 1999; Dani and Bertrand, 2007). Although the mechanisms regulating the localization of nAChRs to the postsynaptic membrane have been relatively well studied (Sanes and Lichtman, 2001), relatively little is known about regulation of nAChR assembly and surface expression.

Although most nAChRs are heteromeric, three are homomeric: $\alpha 7, \alpha 8$, and $\alpha 9$ (Millar, 2003). Studies on the assembly and transport of these simple, homomeric nAChRs have been limited by the difficulty of heterologous expression. Recently, a chaper-

\footnotetext{
Received April 13, 2009; revised Aug. 27, 2009; accepted Sept. 2, 2009.

This work was supported by research grants from the National Institutes of Health (R01-NS038301, R21NS061184), the National Science Foundation (IOS-0641660), and the Muscular Dystrophy Association to Z.-Z.W. We greatly appreciate the gift of plasmid CDNAs and antibodies from Drs. J. M. Lindstrom, Steve Hardy, and David J. Julius. We are grateful to Dr. Jenny Linnoila for helpful discussions and to Dr. Zach Hall for suggesting the model and for help with this manuscript. We thank Dr. Jeannie Chen for help with this manuscript and Dr. Ralf Langen for help with the CD experiments. This paper is dedicated to the memory of Dr. Zuo-Zhong Wang.

${ }^{\dagger}$ Deceased, June 15, 2008.

Correspondence should be addressed to Dr. Ying Wang, University of Southern California, 1501 San Pablo Street, Room 423, Los Angeles, CA 90033. E-mail: yingw17@usc.edu.

D01:10.1523/JNEUROSCI.1776-09.2009

Copyright $\odot 2009$ Society for Neuroscience $\quad$ 0270-6474/09/2912625-11\$15.00/0
}

one, RIC-3 (resistant to inhibitors of cholinesterase), has been identified that facilitates $\alpha 7$ surface expression (Millar, 2008). The gene for RIC-3 was originally identified in genetic screens of Caenorhabditis elegans (Miller et al., 1996), in which the protein is required for expression of multiple nAChRs (Halevi et al., 2002). Related genes occur in both vertebrates and other invertebrates (Halevi et al., 2003). Coexpression studies have shown that RIC-3 affects expression of nAChRs and the closely related serotonin receptors, but not that of GABA, glycine or glutamate receptors (Halevi et al., 2002, 2003). Among mammalian receptors that have been examined, RIC- 3 most prominently affects the expression of the homomeric $\alpha 7 \mathrm{nAChR}$. Functional $\alpha 7 \mathrm{nAChR}$ is expressed poorly in transfected mammalian cell lines that lack endogenous $\alpha 7$ expression (Sweileh et al., 2000), but coexpression of RIC-3 dramatically boosts the levels of functional $\alpha 7$ (Castillo et al., 2005; Lansdell et al., 2005; Williams et al., 2005). Moreover, the extent of endogenous $\alpha 7$ expression is correlated with levels of RIC-3 (Williams et al., 2005), which appears to be localized largely in the ER (Halevi et al., 2002; Castillo et al., 2005; Cheng et al., 2007).

The conserved primary sequence of RIC-3 consists of a short hydrophilic $\mathrm{N}$ terminus, two hydrophobic segments, and a long C-terminal region that contains either one (Drosophila, mouse, human, and Xenopus) or two (C. elegans) coiled-coil domains (Halevi et al., 2003). The processing and transmembrane topology of the protein have been controversial. The lack of agreement has led to two different predictions for the transmembrane topology of the mammalian protein (Fig. 1): RIC-3 either crosses the 

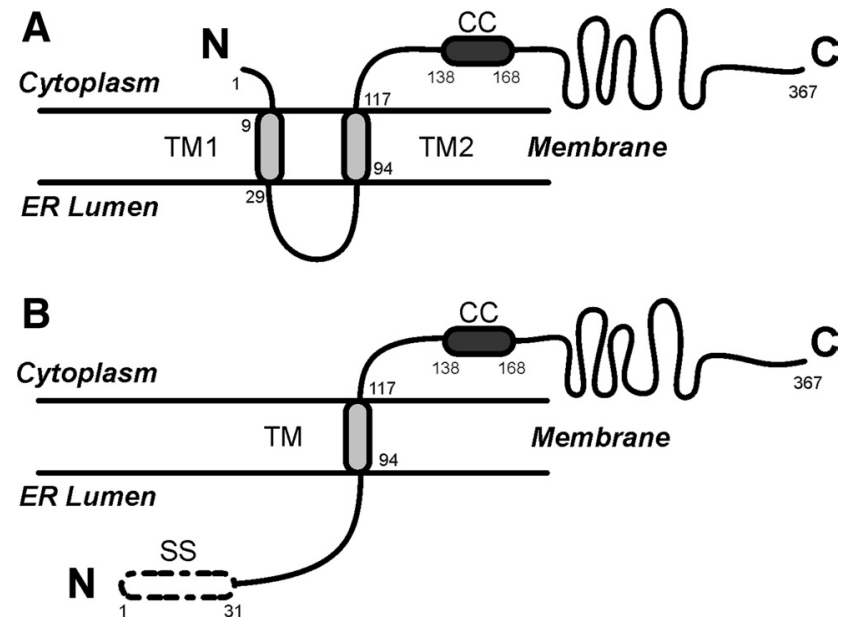

Figure 1. Two models of the transmembrane topology of mouse RIC-3. A, A type III transmembrane protein that crosses membrane twice with both the $\mathrm{N}$ - and C-terminal ends on the cytoplasmic side. The predicted transmembrane segments are composed of residues 9-29 and 94-117, respectively. Residues 138-168 form a coiled-coil domain. $\boldsymbol{B}$, A type I protein that has a single transmembrane segment with the $\mathrm{N}$ terminus on the lumenal side and the $\mathrm{C}$ terminus on the cytoplasmic side of the ER. In this model the first 31 residues are cleaved off and residues 94-117 form a transmembrane region. SS, Signal sequence; TM, transmembrane domain; CC, coiled-coil domain.

ER membrane twice with both $\mathrm{N}$ and $\mathrm{C}$ termini on the cytoplasmic side (Castelán et al., 2008); or has an N-terminal signal peptide and a single transmembrane segment with the $\mathrm{N}$ terminus on the lumenal side (Cheng et al., 2007).

We investigated the membrane topology of mouse RIC-3 (mRIC-3) protein and have used the simplicity of the $\alpha 7$ system to investigate its role in $\mathrm{nAChR}$ assembly. We find that $\mathrm{mRIC}-3$ is a type I protein with a single transmembrane segment that is localized to the ER by a cleavable signal sequence. We further find that RIC-3 facilitates folding of $\alpha 7$ subunits and their assembly into mature receptors, and that, contrary to previous reports with mammalian receptors, $\alpha 7$ assembly requires the coiled-coil domain of mRIC-3, which we show is also required for self-association.

\section{Materials and Methods}

Antibodies and reagents. We generated a rabbit polyclonal antibody against a synthetic peptide consisting of the last 19 amino acid residues of the C terminus of mouse RIC-3 ( ${ }^{349}$ TDNAHVGGMLRKRNPQGFE ${ }^{367}$ ) (Genemed Synthesis). The antibody was immunoaffinity-purified on an Affi-Gel 10 column (Bio-Rad Laboratories). The monoclonal anti-GFP antibody (MMS-118R) and the polyclonal antibody against GPP130 (PRB-144C) were purchased from CRP. The monoclonal anti-protein disulfide isomerase (anti-PDI) antibody (MA3-018) was purchased from Affinity Bioreagents and the monoclonal anti-BiP antibody (SPA-827) from Stressgen Biotechnologies. Wheat germ agglutinin (WGA)-Alexa 488 was obtained from Invitrogen. The monoclonal myc-tag antibody mAb9E10 was purchased from Covance Research Products. Monoclonal anti- $\alpha 7$ antibody mAb319 was a gift from Dr. J. M. Lindstrom (University of Pennsylvania). Purified rabbit and mouse IgGs as well as fluorophore-conjugated secondary antibodies were purchased from Jackson ImmunoResearch Laboratories. Restriction enzymes for DNA subcloning were products of New England Biolabs and Invitrogen. Synthetic oligonucleotide primers were made by Integrated DNA Technology. Cell culture medium and supplements were purchased from Mediatech. All other chemicals were obtained from Sigma-Aldrich.

cDNA constructs. A cDNA encoding the full-length mouse RIC-3 (GenBank accession number: XM_146047) was amplified from an embryonic mouse brain cDNA library (DML-110, Origene), using the PCR with synthetic oligonucleotide primers, and inserted into the pcDNA3 (Invitrogen), pEGFP-N1, pEGFP-C1 (Clontech) and pcDNA3.1(-)-myc vectors (Invitrogen). Modification of $\mathrm{N}$-linked glycosylation $(\mathrm{N}$ glycosylation) sites in the mouse RIC-3 protein were performed using the Quick-Change XL Site-directed Mutagenesis kit following the manufacturer's protocol (Stratagene). Oligonucleotide N128Q changed the protein sequence of mouse RIC-3 from ${ }^{128} \underline{\mathrm{NCS}^{130}}$ to ${ }^{128} \underline{\mathrm{Q}} \mathrm{CS}^{130}$, abolishing the original potential $\mathrm{N}$-linked glycosylation consensus sequence. The other oligonucleotides (H53N, K117N, V167S, H353S) introduced novel consensus sequences of $\mathrm{N}$-linked glycosylation by converting sequences ${ }^{53} \mathrm{HHS}^{55},{ }^{117} \mathrm{KLS}^{119},{ }^{165} \mathrm{NRV}^{167}$, and ${ }^{351} \mathrm{NAH}^{353}$ to ${ }^{53} \mathrm{NHS}^{55},{ }^{117} \mathrm{NLS}^{119}$, ${ }^{165} \mathrm{NRS}{ }^{167}$, and ${ }^{351} \mathrm{NA} \underline{S}^{353}$, respectively. All truncation and deletion mutations of mRIC- 3 were generated by PCR and subcloning. cDNA encoding the full-length $\alpha 7$ subunit of human nAChR in the vector pXMT, which was a gift from Dr. J. M. Lindstrom (University of Pennsylvania), was subcloned into the vector pcDNA3.1(-). The mouse serotonin receptor $\left(5-\mathrm{HT}_{3 \mathrm{~A}}\right)$ cDNA in the vector pcDNA3 was a gift from Dr. David Julius (University of California, San Francisco). The plasmid pcDNA3.1(-)- $\alpha 7$ (V201)5HT3A was generated by in-frame fusion of a cDNA encoding residues 1-201 in the human nAChR $\alpha 7$ subunit to that coding for the transmembrane, cytoplasmic and C-terminal domains of mouse 5-HT ${ }_{3 \mathrm{~A}}$ (Eiselé et al., 1993).

COS cell transfection. COS-7 and BOSC cells were grown in standard growth medium (DMEM containing $50 \mathrm{I} . \mathrm{U} . / \mathrm{ml}$ penicillin, $50 \mathrm{mg} / \mathrm{ml}$ streptomycin, 2 mM L-glutamine, 10\% fetal bovine serum) until $70-80 \%$ confluence. The cells were transfected with various plasmids using an adenovirus-mediated DEAE-dextran method as previously described (Forsayeth and Garcia, 1994).

Cell lysate preparation. Approximately $48 \mathrm{~h}$ after transfection, cells were rinsed with PBS, scraped off the dish, and lysed in ice-cold extraction buffer (50 mu Tris, pH 7.4, 50 mm NaCl, 1\% NP40, 1 mm EDTA, 1 mM EGTA) supplemented with a protease inhibitor mixture (1\% P8340 and $40 \mathrm{~mm}$ PMSF, Sigma-Aldrich). After a brief incubation on ice $(\sim 10$ $\mathrm{min}$ ), the mixture was centrifuged at $14,000 \mathrm{rpm}$ for $5 \mathrm{~min}$ at $4^{\circ} \mathrm{C}$ to remove insoluble materials. The extracts were then either subjected to immunoprecipitation or heated at $75^{\circ} \mathrm{C}$ for $10 \mathrm{~min}$ in NuPAGE LDS sample buffer with reducing agents.

Immunoprecipitation and immunoblotting. Detergent extracts of $\mathrm{COS}$ cells were incubated at $4^{\circ} \mathrm{C}$ with the appropriate antibodies overnight followed by Protein-A Sepharose beads (GE Healthcare) for $1 \mathrm{~h}$. Purified rabbit or mouse $\operatorname{IgG}(2 \mu \mathrm{g} / 100 \mu \mathrm{l})$ was used as a negative control. The beads were collected by centrifugation and washed with the extraction buffer three times. Bound proteins were eluted by heating the beads at $95^{\circ} \mathrm{C}$ for 5 min in NuPAGE LDS sample buffer with reducing agents.

Protein samples were separated on 4-12\% NuPAGE Novex Bis-Tris precast gels (Invitrogen), and transferred onto nitrocellulose membranes on a Bio-Rad Trans-Blot SD semidry transfer cell. The membranes were preblocked with $5 \%$ bovine serum albumin in Tris-buffered saline (TBS) at room temperature for $2 \mathrm{~h}$, and then incubated with the appropriate primary antibodies in the blocking buffer with $0.1 \%$ Tween 20 at $4{ }^{\circ} \mathrm{C}$ overnight. After a brief washing in TBS containing $0.1 \%$ Tween 20 , the membranes were incubated for $1 \mathrm{~h}$ at room temperature in the dark with Alexa Fluor-conjugated secondary antibodies and rinsed extensively with 0.1\% Tween 20/TBS. Protein bands bound to the antibodies were visualized by scanning the membranes in an Odyssey Infrared Imaging System (LI-COR).

Immunofluorescence staining. Cells were fixed in $4 \%$ paraformaldehyde or ice-cold methanol for $5 \mathrm{~min}$, and permeabilized and blocked in PBS containing 10\% normal goat serum and $0.1 \%$ Triton for 30 min. They were then incubated with primary antibodies followed by fluorophore-conjugated secondary antibodies, and examined under an Olympus FluoView-1000 confocal microscope with the appropriate laser lines.

Deglycosylation. The cell lysates were treated with either endoglycosidase $\mathrm{H}$ (Endo $\mathrm{H}$ ), or $\mathrm{N}$-glycosidase F (PNGase F), following a protocol suggested by the manufacturer (New England Biolabs). Deglycosylated samples were subjected to immunoblotting assay as described above.

Radioligand binding assay. The levels of $\alpha 7 \mathrm{nAChRs}$ and the chimeric receptor $\alpha 7$ (V201)-5 $5 \mathrm{HT}_{3 \mathrm{~A}}$ on the COS cell surface were determined as 

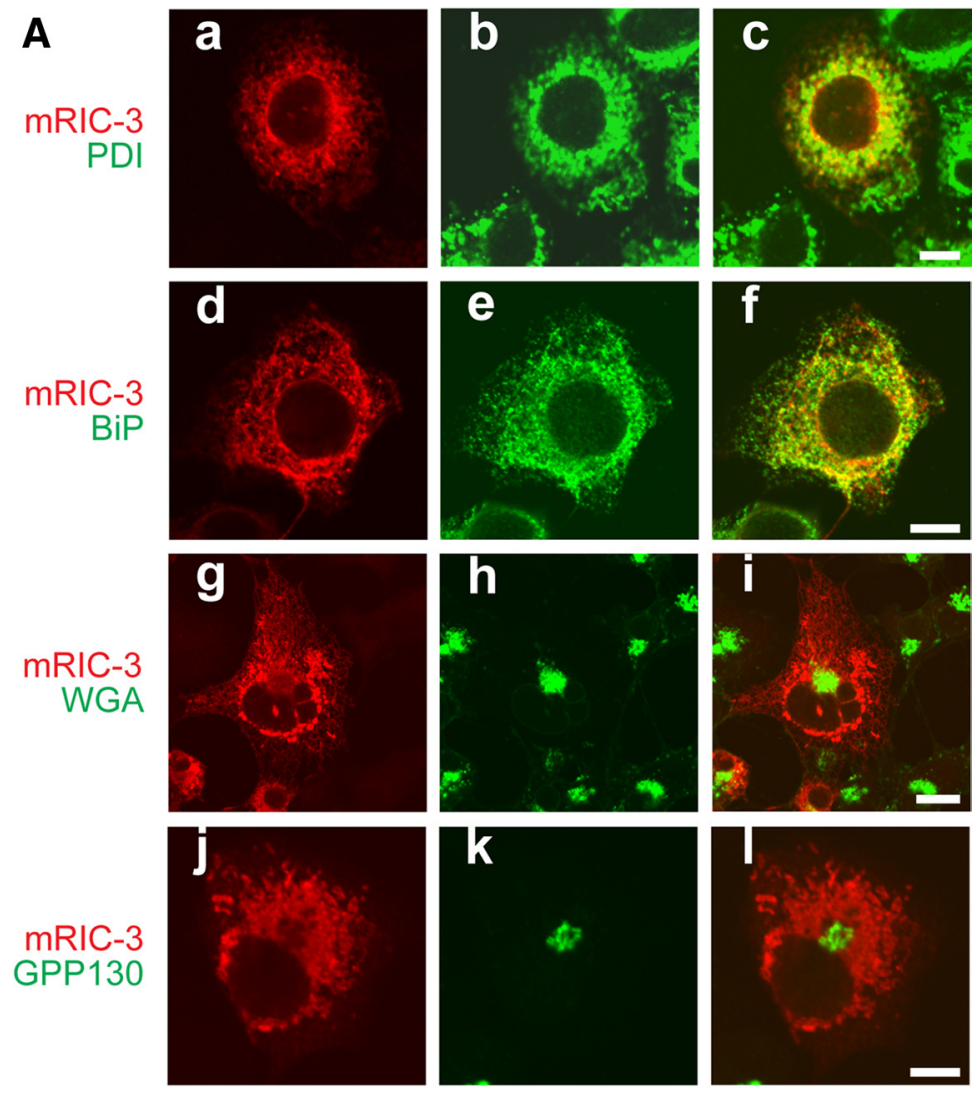

B
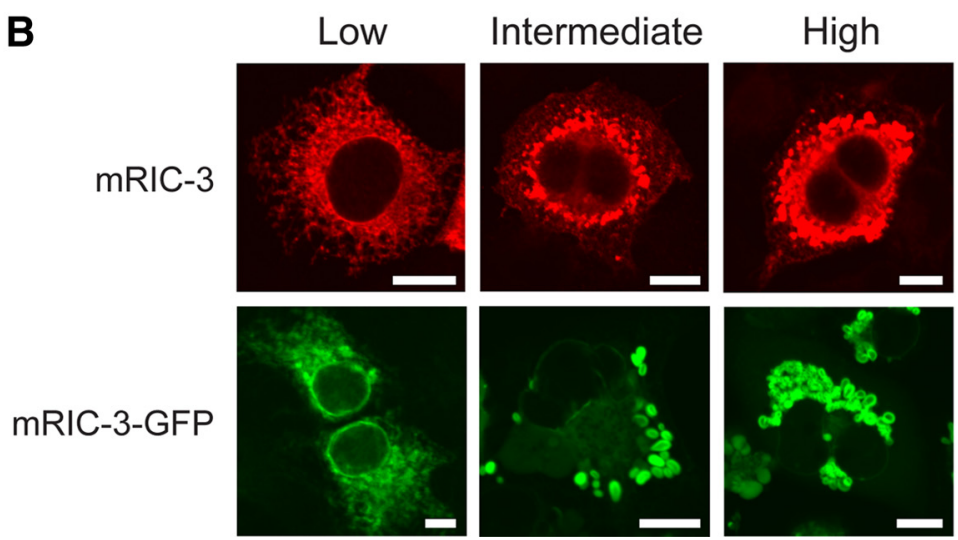

Figure 2. Mouse RIC-3 is predominantly localized in the ER. A, COS cells transfected with mRIC-3 were double labeled with anti-mRIC-3 antibody (red) along with antibodies against PDI (green, $\boldsymbol{a}-\boldsymbol{c}$ ) or BiP (green, $\boldsymbol{d}-\boldsymbol{f}$ ). The merged images show strong colocalization (yellow) of mRIC-3 and these resident ER proteins. In contrast, costaining with WGA (green, $\boldsymbol{g}-\boldsymbol{i}$ ) or anti-GPP130 (green, $\boldsymbol{j}-I$ ), both Golgi markers, shows little overlap with mRIC-3 labeling. $\boldsymbol{B}$, COS cells expressing either mRIC-3 (top) or mRIC3GFP (bottom) at different levels were immunostained (top) or observed using live-cell imaging (bottom). At low levels of expression, both mRIC-3 and mRIC-3-GFP localize to a branching network of tubules. These tubules became increasingly vesiculated and enlarged as the expression level increased. Scale bars, $10 \mu \mathrm{m}$.

described (Yu and Hall, 1994). Briefly, intact transfected cells were incubated for $90 \mathrm{~min}$ in fresh growth medium supplemented with $0.5 \mu \mathrm{Ci} / \mathrm{ml}$ ${ }^{125} \mathrm{I}$ - $\alpha$-bungarotoxin $(\alpha$-BTX) (Perkin-Elmer). After a brief washing with PBS to remove excessive ${ }^{125} \mathrm{I}-\alpha$-BTX, bound toxins (total binding) were measured by solubilizing the cells in $0.2 \mathrm{~N} \mathrm{NaOH}$ and counting the radioactivity in a gamma counter. Specific binding was calculated by subtracting nonspecific binding, which was measured by using shamtransfected cells, from the total binding.

The total amount of $\alpha 7$ subunit with toxin-binding activity in COS cells was determined by radioligand binding followed by immunoprecipitation (Wang et al., 1996a). $\alpha$-BTX has been previously shown to bind both partially and completely assembled $\alpha 7$ subunits (Sweileh et al.,
2000). $1 \mu \mathrm{Ci} / \mathrm{ml}^{125} \mathrm{I}-\alpha$-BTX was added to the cell lysate together with rat anti- $\alpha 7$ antibody. After incubation at $4^{\circ} \mathrm{C}$ overnight, secondary antibody rabbit anti-rat $\operatorname{IgG}$ was added to the mixture for $30 \mathrm{~min}$ before precipitation with PANSORBIN cells (Calbiochem) according to the manufacturer's protocol. The pellets were collected and the radioactivity (total binding) was counted in a gamma counter. Rat IgG was used instead of anti- $\alpha 7$ antibody to measure nonspecific binding, which was subtracted from the total binding for calculation of specific binding.

Depletion of the toxin-binding forms of $\alpha 7$ $n A C h R$. Lysates of transiently transfected cells (uncleared lysates) were incubated at $4^{\circ} \mathrm{C}$ with $\alpha$-BTX conjugated to agarose beads (Ferns et al., 1996) for $2 \mathrm{~h}$. The supernatant (cleared lysates) were collected and subjected to immunoprecipitation. Incubation of the supernatant with ${ }^{125} \mathrm{I}-\alpha$-BTX, followed by immunoprecipitation with anti- $\alpha 7$ antibody showed that no toxin-binding activity remained.

Whole-cell patch-clamp recording. BOSC cells were cotransfected with pEGFP-N1 and human $\alpha 7$ cDNA with or without mRIC-3 constructs. Whole-cell recordings were performed only in GFP-positive cells at $\sim 48 \mathrm{~h}$ after transfection. Trypsinized cells were plated on poly-lysine-coated $35 \mathrm{~mm}$ culture dishes and placed on the stage of an inverted microscope (IX70; Olympus). A constant superfusion was applied with standard external solution $(120 \mathrm{~mm} \mathrm{NaCl}, 3 \mathrm{~mm} \mathrm{KCl}, 2 \mathrm{~mm}$ $\mathrm{MgCl}_{2}, 2 \mathrm{~mm} \mathrm{CaCl}$, $25 \mathrm{~mm}$ D-glucose, $10 \mathrm{~mm}$ HEPES, pH 7.4). Cells were then voltage clamped at holding potentials of $-120 \mathrm{mV}$, and ion currents in response to application of acetylcholine (ACh) were recorded with glass microelectrodes (3-5 $\mathrm{M} \Omega$ resistance) filled with internal solution (110 mm Tris phosphate dibasic, $28 \mathrm{~mm}$ Tris base, $11 \mathrm{~mm}$ EGTA, $2 \mathrm{~mm}$ $\mathrm{MgCl}_{2}, 0.1 \mathrm{~mm} \mathrm{CaCl}_{2}, 4$ mм Na-ATP, pH 7.3) via an Axopatch 200B amplifier (Molecular Devices). The rapid application of ACh was achieved by perfusion fast-step system (SF77B; Warner Instruments). The pClamp10 program (Molecular Devices) was used to acquire and analyze data.

Circular dichroism spectroscopy. A peptide of 32 aa corresponding to the predicted coiled-coil domain of mouse RIC-3 ( ${ }^{137}$ AHRKITNFELVQLQEKLKETEEAMEKLINRVG ${ }^{168}$ ) was synthesized (Biomer Tech). The $\mathrm{N}$ terminus of the peptide was acetylated and the $C$ terminus was amidated to avoid introducing additional charge interactions. The peptide was dissolved in $10 \mathrm{~mm}$ sodium phosphate buffer, $\mathrm{pH} 7.4$, and the peptide concentration determined by bicinchoninic acid assays (Pierce Biotechnology). Circular dichroism (CD) spectra were obtained at $25^{\circ} \mathrm{C}$ using a Jasco 815 spectropolarimeter (Jasco) in a 1 or $10 \mathrm{~mm}$ path length quartz cuvette. Data were collected either between 191 and $260 \mathrm{~nm}$ ( $5 \mu \mathrm{M}$ sample) or between 201 and $260 \mathrm{~nm}$ (270 $\mu \mathrm{M}$ sample). Spectra were recorded at a scanning rate of $50 \mathrm{~nm} / \mathrm{min}$, a data pitch of $0.1 \mathrm{~nm}$, with a response time of $1 \mathrm{~s}$ and 32 accumulations. The buffer was used for background correction. The mean residue molar ellipticity $\left([\Theta]\right.$, deg $\mathrm{cm}^{2} \mathrm{dmol}^{-1}$ ) calculated from the following equation: $[\Theta]=\theta / n C l$, where $\theta$ is the measured ellipticity in degrees, $n$ represents the number of residues, $l$ is the path length of the cuvette in 
millimeters, and $C$ is the molar concentration (Jayasinghe and Langen, 2005). The fractional percentage of $\alpha$-helix was estimated from $[\Theta]_{222} \mathrm{~nm}$ by $100 \% \alpha$-helix $=-40,000[1-(2.5 / n-1)]$, where $n$ represents the number of residues (Joyce et al., 2002).

\section{Results}

\section{mRIC-3 is an ER protein}

Previous studies have reported a perinuclear localization of human and C. elegans RIC-3 in neurons and transfected mammalian cell lines (Halevi et al., 2002, 2003; Castillo et al., 2005; Castelán et al., 2008), suggesting that it may be localized in the ER. The finding that the protein binds to unassembled nAChR subunits (Lansdell et al., 2005; Williams et al., 2005) is consistent with this hypothesis. We examined the subcellular localization of mouse RIC-3 after transfection into COS cells by colabeling the cells with antibodies to mRIC-3 and to two endogenous resident proteins of the ER, PDI and $78 \mathrm{kDa}$ glucose-regulated protein (GRP78/BiP) (Fig. 2Aa-Af). The extensive overlap of the ER markers (Luz and Lennarz, 1996; Gething, 1999) with mRIC-3 demonstrates clearly that RIC-3 is an ER protein, in agreement with the results of Cheng et al. (2007). In contrast, mRIC-3 did not colocalize well with the fluorescently labeled Golgi marker, WGA (Virtanen et al., 1980; Li et al., 1995) (Fig. 2 Ag$A i)$ or with GPP130 (Linstedt et al., 1997; Bachert et al., 2001; Puri et al., 2002) a transmembrane protein specific for the cis-Golgi (Fig. $2 A j-A l$ ). The area adjacent to the regions labeled by the cis-Golgi marker, which is presumably trans-Golgi, was also not stained well by mRIC-3 antibody. Thus, mRIC-3 is localized predominantly within the ER.

The pattern of distribution of mRIC-3 and of mRIC-3 coupled to GFP (see below) changed when either protein was overexpressed in COS cells. At low levels of expression, the proteins were distributed uniformly in a perinuclear network of branching tubules, typical of ER morphology in cultured cells (Fig. 2B, left). This labeling pattern changed dramatically with higher levels of expression of either protein when intensely fluorescent, nonbranching vesiculated structures were observed adjacent to the nuclear envelope and in the cell periphery (Fig. $2 B$, middle). The number of the nonbranching vesicular accumulations increased further with even higher expression levels of either protein (Fig. $2 \mathrm{~B}$, right). The bright oval structures resemble the organized smooth ER or crystalloid ER, induced by overexpression of resident ER transmembrane proteins via homotypic interactions between cytoplasmic domains of the proteins (Yamamoto et al., 1996; Snapp et al., 2003). Similar structures were seen by Cheng et al. (2007), using human RIC-3, who described them as aggregates. Because crystalloid ER is seen at high levels of expression of other resident ER proteins, these observations further confirm that RIC-3 is an ER protein.

D

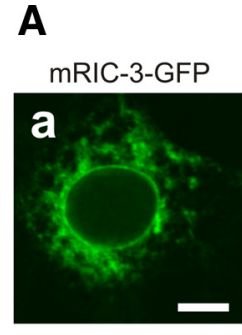

B
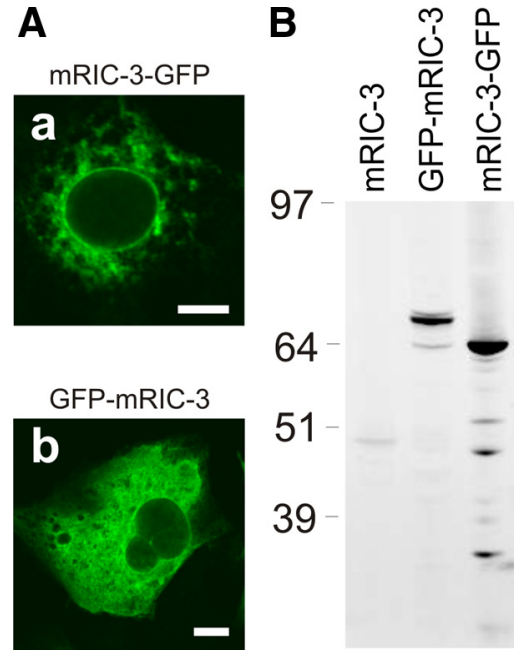

64

97

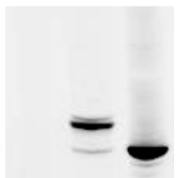

51

39

Figure 3. The $\mathrm{C}-$ and $\mathrm{N}$-terminally tagged $\mathrm{mRIC}-3$ proteins differ in both subcellular localization and protein size. $A$, Live-cell images of $C O S$ cells expressing GFP tagged at the $C$ terminus $(\boldsymbol{a})$ or the N terminus ( $\boldsymbol{b})$ of mRIC-3. The C-terminally tagged mRIC-3-GFP $(\boldsymbol{a})$ showed a normal ER localization pattern, while the N-terminally tagged GFP-mRIC-3 $(\boldsymbol{b})$ showed a diffuse distribution in the cell. Scale bars, $10 \mu \mathrm{m}$. $\boldsymbol{B}$, Western blot of COS cells transfected with untagged $\mathrm{mRIC}-3$ or GFP-tagged mRIC-3 constructs detected with an anti-GFP antibody. The N-terminally tagged GFP-mRIC-3 is larger than the C-terminally tagged mRIC-3-GFP by $\sim 4 \mathrm{kDa}$.
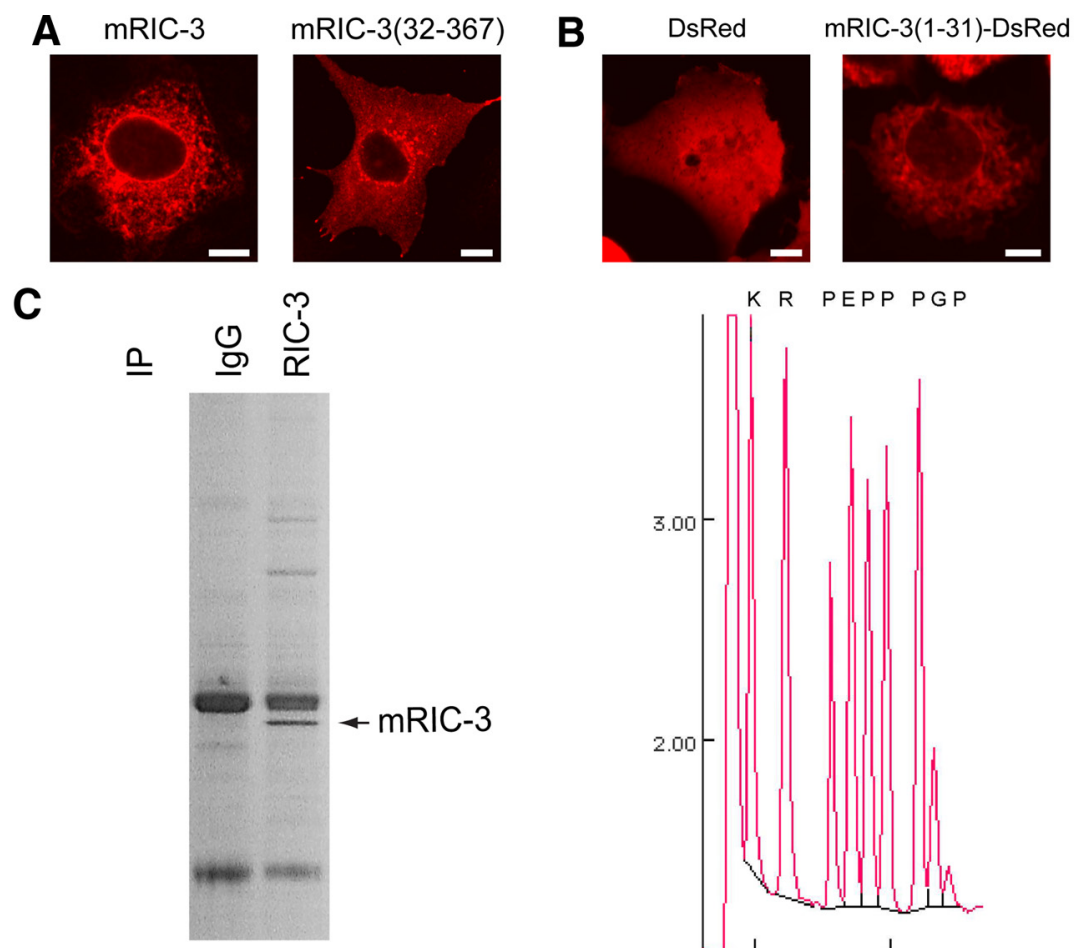

$K$ R PEPP PGP

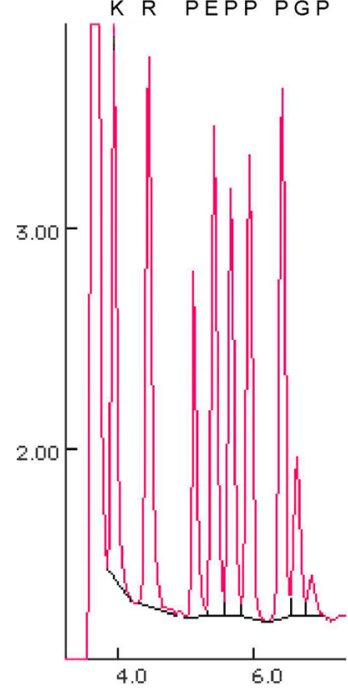

\section{MAYSTVORVALASGLVIAVSLILPKAFLSRGKRPEPPPGPEGKDDEPPMMHHHSAPSDG SS}

Figure 4. Residues 1-31 of mRIC-3 constitute a signal peptide that directs protein localization to the ER. $A$, COS cells expressing either full-length mRIC-3 or mRIC-3(32-367) were fixed, permeabilized, and labeled with anti-mRIC-3 antibody. When the $\mathrm{N}$-terminal 31 aa are deleted, $\mathrm{mRIC}-3$ is no longer located to the ER. $\boldsymbol{B}$, Live-cell images of COS cells transfected with DsRed vector or mRIC-3(1-31)-DsRed. Untagged DsRed is soluble and shows a diffuse localization pattern (left), whereas fusion of residues 1-31 of mRIC-3 to DsRed leads to the ER localization of the protein (right). Scale bars, $10 \mu \mathrm{m}$. C, COS cells overexpressing mRIC-3 were lysed and immunoprecipitated (IP) with a rabbit RIC-3 antibody. Rabbit lgG was used as a control. The Coomassie staining revealed a visible band corresponding to the molecular weight of $\mathrm{mRIC}-3$, which was excised from the gel and subjected to N-terminal sequencing by Edman degradation (right). D, Primary sequence of mouse RIC-3 N terminus. The amino acids identified in Edman degradation are marked with the red box. The cleavable signal sequence (SS) is underlined. 


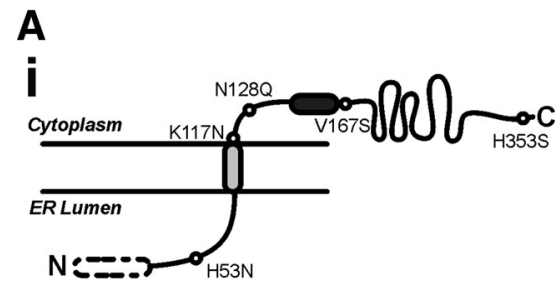

C
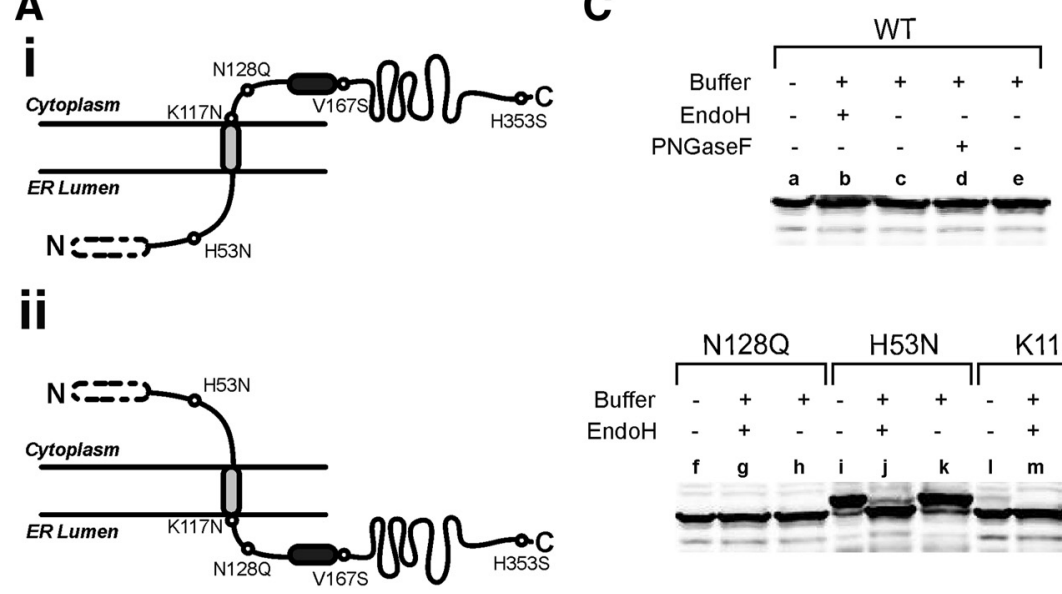

B

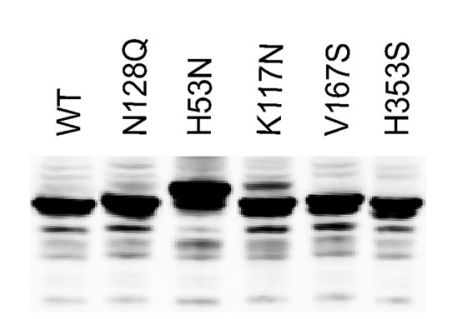

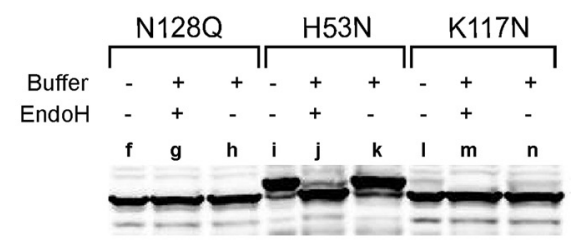

D

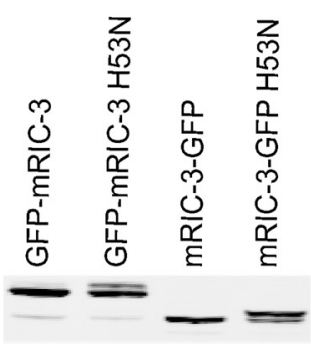

Figure 5. Residue $\mathrm{H} 53$ of mRIC -3 resides in the ER lumen. $\boldsymbol{A}$, Schematic diagram of the glycosylation site mutant constructs of mRIC-3. B, COS cells transiently transfected with mRIC-3 wild-type (WT) or mutant CDNA constructs were lysed and analyzed by Western blot. Among all the samples, only mRIC-3 H53N appeared as a higher-molecular-weight species, consistent with its being $\mathrm{N}$-glycosylated. C, To verify that mRIC-3 H53N is glycosylated, lysates of cells overexpressing either WT mRIC-3 (lanes a-e) or mRIC-3 mutants (lanes $\mathrm{f}-\mathrm{n}$ ) were treated with Endo H, PNGase F, or the corresponding buffers, followed by Western blot analysis. mRIC- $3 \mathrm{H} 53 \mathrm{~N}$ is sensitive to Endo H, confirming that it is glycosylated in the ER. D, COS cells transfected with control GFP-tagged mRIC-3 constructs or corresponding mutants with engineered glycosylation site were lysed and analyzed by Western blot.

\section{mRIC-3 has a cleavable signal peptide that directs the protein} to the ER

To investigate the mechanism of localization of RIC-3 to the ER, either the $\mathrm{N}$ or the $\mathrm{C}$ terminus of mouse RIC-3 was tagged with GFP and the recombinant proteins expressed in COS cells. Their localization was strikingly different. C-terminally tagged mRIC-3 (mRIC-3-GFP) showed a perinuclear pattern of staining (Fig. $3 A a)$ similar to untagged mRIC-3 (Figs. $2 B, 4 A$ ), indicating localization in the ER. The N-terminally tagged mRIC-3 (GFPmRIC-3), however, showed a diffuse cellular distribution (Fig. $3 A b$ ). Western blot analysis showed that expressed GFP-mRIC-3 was $\sim 4 \mathrm{kDa}$ larger than mRIC-3-GFP (Fig. $3 B$ ), indicating that $\mathrm{N}$-terminal cleavage of the C-terminally tagged RIC-3 had occurred. These observations suggest that mRIC-3 has a cleavable signal peptide that directs it to the ER.

As signal peptides are known to be both necessary and sufficient for ER targeting, we deleted the first 31 aa at the $\mathrm{N}$ terminus of $\mathrm{mRIC}-3$ and expressed the truncated protein in COS cells to examine its subcellular localization. Immunostaining showed a diffuse pattern of distribution, with slight perinuclear staining (Fig. 4A), indicating reduced ER localization. To determine whether the $\mathrm{N}$-terminal sequence is sufficient to target proteins to the ER, we attached it to DsRed (Bell et al., 2007), a red fluorescent protein that is normally cytoplasmic. Fluorescence imaging showed that mRIC-3(1-31)-DsRed was located in the ER in the transfected COS cells (Fig. $4 \mathrm{~B}$ ). Attachment of mRIC-3 residues 1-31 to a cytoplasmic protein is thus sufficient to target it to the ER. Similar results have been reported by Cheng et al. (2007).
Protein sequencing was performed to determine the site of cleavage. Lysates of COS cells expressing mRIC-3 were immunoprecipitated with RIC-3 antibody, the immunoprecipitates run on an SDS-PAGE gel and the band corresponding to mRIC-3 (judged by molecular weight) (Fig. 4C) excised from the gel and analyzed by Edman degradation. Sequencing demonstrated that the $\mathrm{N}$ terminus of the mature mouse RIC-3 is lysine 32 (K32) (Fig. 4D).

\section{mRIC-3 is a type I}

transmembrane protein

Glycosylation experiments were performed to determine the orientation of mRIC-3 in the ER membrane (Chavez and Hall, 1991). We first examined whether native $\mathrm{mRIC}-3$ is a glycoprotein (Kornfeld and Kornfeld, 1985). The primary amino acid sequence of mRIC-3 contains a single consensus site (NXT/S) for $N$-glycosylation at N128. To determine whether this site is glycosylated, lysates of COS cells transfected with mRIC-3 were treated with Endo H or PNGase F (Spellman, 1990; Plummer and Tarentino, 1991) and then analyzed by Western blotting. Treatment with neither enzyme reduced the mobility of the protein (Fig. 5C, lanes $\mathrm{b}$ and $\mathrm{d}$ ), suggesting that $\mathrm{mRIC}-3$ is normally not glycosylated. Consistent with this idea, a point mutation $(\mathrm{N} 128 \mathrm{Q})$ that abolishes the potential glycosylation site did not affect the size of the expressed protein (Fig. 5B). Thus, residue N128 is not glycosylated, presumably because it is not in the ER lumen.

Next, we introduced artificial glycosylation sites at other sites of RIC-3 either preceding (mRIC-3 H53N), or following (mRIC-3 K117N, V167S, H353S), the putative transmembrane domain. When the resulting proteins were analyzed after expression in COS cells, only mRIC-3 H53N migrated more slowly than the wild-type protein (Fig. $5 B$ ), and was sensitive to Endo $\mathrm{H}$ digestion (Fig. $5 C$, lane j). Thus residue $\mathrm{H} 53$ of mRIC-3 is in the ER lumen. Because the carbohydrate chain on the introduced consensus sequence was sensitive to Endo $\mathrm{H}$, the protein is most likely retained on the ER membrane without recycling between the ER-Golgi compartments (Nicke et al., 2004). Mutated sites K117, V167, and H353 were not glycosylated, implying that these sites are located in the cytoplasm. Since hydrophobicity analysis shows that neither residues 32-93 nor residues $117-367$ of the protein comprise membrane-spanning segments, residues 32-93 are likely on the lumenal side of the ER membrane and residues 117-367 on the cytoplasmic side. Together, these results are consistent with the signal peptide model and exclude the possibility that the C-terminal tail of mouse RIC-3 is in the ER lumen.

We further tested the topology of mRIC-3 by introducing the $\mathrm{H} 53 \mathrm{~N}$ glycosylation consensus sequence into the GFP-tagged mRIC-3 constructs, into mRIC3-GFP, which is localized in the cytoplasm, and into GFP-mRIC3, which is diffusely distributed (Fig. 5D). Like mRIC-3 H53N, most of mRIC-3-GFP H53N was glycosylated, consistent with its localization in the ER (Fig. $2 B$ ). Interestingly, a small portion of GFP-mRIC-3 H53N was also glyco- 
sylated, suggesting that, while most of the GFP-mRIC-3 was not accessible to the site of glycosylation in the ER lumen, a small fraction did gain ER access despite having a blocked signal sequence. The observed difference in glycosylation of the two GFPtagged constructs confirms the lumenal localization of the glycosylation site $\mathrm{H} 53 \mathrm{~N}$, as well as the importance of the $\mathrm{N}$-terminal signal peptide for ER localization.

In sum, the results derived from immunofluorescence staining, protein sequencing and site-directed mutagenesis support the model that the mouse RIC-3 is a single-pass type I transmembrane protein with its signal sequence-cleaved $\mathrm{N}$ terminus residing in the lumen of ER and the coiled-coil domain in the cytoplasm.

Functional domains of mRIC-3

To investigate the mechanisms by which mRIC-3 facilitates folding and assembly of $\alpha 7 \mathrm{nAChR}$, we performed systematic mutagenesis studies (Fig. 6A) to define the role of each domain. Western blot analysis indicated that all constructs were expressed at levels comparable to wildtype mRIC-3 (supplemental Fig. $1 A, B$, available at www.jneurosci.org as supplemental material). Immunofluorescence staining showed a pattern consistent with ER localization for all constructs except those with N-terminal deletions, which showed a more diffuse cytoplasmic distribution with reduced ER localization (supplemental Fig. 1C, available at www. jneurosci.org as supplemental material), similar to that observed in Figure $4 A$. Consistent with other reports (Castillo et al., 2005; Lansdell et al., 2005; Williams et al., 2005), no toxin-binding activity was detected on the cell surface when $\alpha 7$ was expressed alone in COS cells (Fig. 6B), but when mRIC-3 was coexpressed, the number of surface toxin-binding sites was dramatically increased. N-terminal truncations of mRIC-3 severely reduced its ability to enhance surface toxin-binding activity, consistent with the idea that expression of mRIC-3 in the ER is necessary for its functional activity. The remaining activity is likely due to limited ER access in the absence of a signal sequence (Fig. 5D). In contrast, C-terminal truncations of mRIC-3 with intact coiled-coil domains performed as well as, or better than, the full-length mRIC-3, with respect to enhancement of $\alpha 7$ surface expression. Truncation of all, or part of, the coiled-coil domain on the $\mathrm{C}$ terminus, on the other hand, resulted in a significant reduction in mRIC-3 function, as did removal of the hydrophilic proline-rich region before the transmembrane segment (Fig. 6B).

Experiments on the expression of exogenous $5-\mathrm{HT}_{3}$ receptor in Xenopus oocytes have shown that RIC-3 reduces, rather than increases, surface expression of the receptor (Halevi et al., 2003; Castillo et al., 2005). Moreover, the surface expression of a chi-
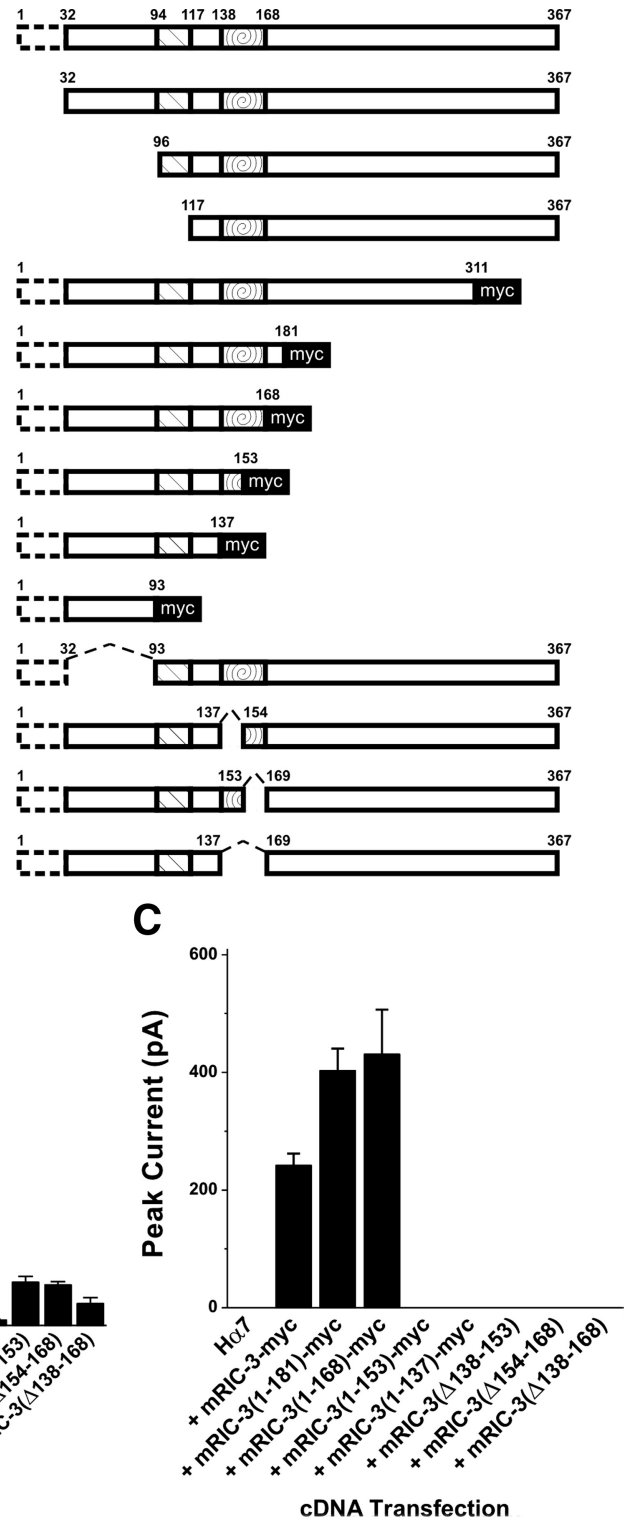

cDNA Transfection

Figure 6. Residues 1-168 comprise the minimal functional domain of $\mathrm{mRIC}-3 . \boldsymbol{A}$, Schematic diagram of the truncated fragments and deletion mutations of mouse RIC-3 protein used for transfection. $\boldsymbol{B}, \operatorname{COS}$ cells were transfected with human $\alpha 7 \mathrm{nAChR}$ CDNA either alone or together with wild-type or mutated mRIC-3. Surface receptor expression was monitored by ${ }^{125}{ }^{\mathrm{I}}-\alpha$-BTX binding used for each treatment group. C, Summary of inward currents in response to $3 \mathrm{~mm}$ acetylcholine recorded from BOSC cells either transfected with human $\alpha 7$ alone or coexpressing $\alpha 7$ and mRIC -3 mutants. Data were obtained from five cells.

meric receptor, consisting of the N-terminal extracellular domain of $\alpha 7 \mathrm{nAChR}$ and the transmembrane and cytoplasmic domains of the $5-\mathrm{HT}_{3 \mathrm{~A}}$ receptor $\left[\alpha 7(\mathrm{~V} 201)-5 \mathrm{HT}_{3 \mathrm{~A}}\right.$ ] (Eiselé et al., $1993)$, in mammalian cells is also repressed, rather than increased by RIC-3 (Castillo et al., 2005; Gee et al., 2007). We found that all truncation mutants of mRIC-3 that promoted $\alpha 7$ expression consistently suppressed the expression of $\alpha 7(\mathrm{~V} 201)-5 \mathrm{HT}_{3 \mathrm{~A}}$, whereas the mutant proteins which were impaired with respect to facilitation of $\alpha 7$ expression were also deficient in repressing expression of the chimeric receptor (supplemental Fig. $2 \mathrm{~A}$, available at www.jneurosci.org as supplemental material). Thus, with respect to both enhancement of $\alpha 7$ expression or inhibition of the chimeric receptor, residues 1-168 comprise the minimal functional domain of mRIC-3. 
To explore further the effect of mRIC-3 mutants on the surface expression of $\alpha 7$ in single cells, we measured ACh-induced whole-cell currents in BOSC cells transfected with human $\alpha 7$ with or without mRIC-3 (supplemental Fig. $2 B$, available at www.jneurosci.org as supplemental material). The quantified results are shown in Figure 6C. Application of ACh failed to evoke any response from BOSC cells when $\alpha 7$ was expressed alone. In contrast, robust inward currents were readily detected in cells coexpressing $\alpha 7$ and myc-tagged full-length mRIC-3 (mRIC-3$\mathrm{myc}$ ), indicating that the surface receptors are functional. The C-terminal truncations mRIC-3(1-181) and mRIC-3(1-168) also promoted the expression of functional surface receptors. On the contrary, no functional activity was detected with the C-terminal truncated fragments or the mutants without an intact coiled-coil domain. This result of the physiological assay is thus qualitatively consistent with the binding assay results (Fig. $6 \mathrm{~B}$ ). The complete absence of activity detected physiologically may reflect differences either in the assays or in the cell types that are used in the two experiments.

Together, these studies indicate that the $\mathrm{N}$-terminal signal sequence and the coiled-coil domain as well as the hydrophilic region upstream of the transmembrane segment of mRIC-3 are required for enhanced $\alpha 7 \mathrm{nAChR}$ expression.

\section{The role of RIC-3 in the regulation of $\alpha 7$ expression}

Expression of functional surface $\alpha 7 \mathrm{nAChR}$ occurs through a multistep, poorly characterized pathway that includes subunit folding and polymeric assembly in the ER, followed by trafficking to the plasma membrane. Newly synthesized $\alpha 7$ subunit does not bind $\alpha$-BTX, but acquires toxin-binding activity through folding or assembly with other subunits, apparently aided by cellular factors (Sweileh et al., 2000). To determine the site of action of RIC-3, human $\alpha 7$ was expressed in COS cells with and without coexpression of mRIC-3. Analysis of cell lysates by Western blots showed that mRIC-3 coexpression resulted in a modest increase in the total amount of $\alpha 7$ subunit ( $54 \pm 8 \%, n=3$ ) (Fig. 7A). In contrast, mRIC-3 coexpression caused an $\sim 10$-fold increase $(10.1 \pm 1.8, n=4)$ in toxin-binding activity (data not shown), as measured by incubation of cell lysates with ${ }^{125} \mathrm{I}-\alpha$-BTX followed by immunoprecipitation (Wang et al., 1996a). As there is no detectable expression of surface toxin-binding activity in the absence of mRIC-3 (Fig. 6B), the small amount of toxin-binding activity found in the lysates presumably represents unassembled, folded subunits or partially assembled $\alpha 7$ receptors that remain in the ER (Sweileh et al., 2000; Nicke et al., 2004). Our data thus suggest that in the absence of coexpressed mRIC-3, $>85 \%$ of the newly synthesized $\alpha 7$ subunit remains unfolded, and that RIC-3 facilitates surface expression of $\alpha 7$.

The steps toward surface expression of $\alpha 7$ include folding and assembly of the subunits into pentameric receptors in the ER, followed by transport of the pentamers to the cell surface. To investigate the role of RIC-3 in these steps, we first established the interaction between $\alpha 7 \mathrm{nAChR}$ and mRIC-3 by demonstrating that each protein could be immunoprecipitated by antibodies to the other when the two were coexpressed in COS cells (Fig. 7B). We then investigated whether mRIC- 3 binds to $\alpha 7$ subunits before or after they have acquired toxin-binding activity. Immunoprecipitation of lysates with RIC-3 antibody pulled down a significant amount of the total ${ }^{125} \mathrm{I}-\alpha$-BTX binding activity (32 \pm $12 \%, n=4$, data not shown). When the toxin-binding activity in the lysate was removed by incubation with $\alpha$-BTX-conjugated agarose beads, RIC-3/ $\alpha 7$ complexes could be detected in the cleared supernatant by immunoprecipitation with either mAb319 against

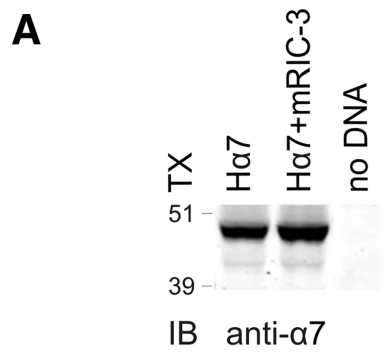

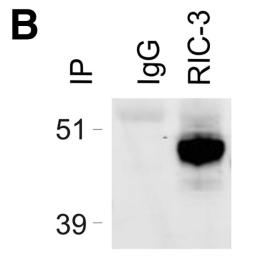

IB: anti- $\alpha 7$

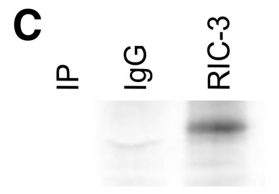

IB: anti- $\alpha 7$

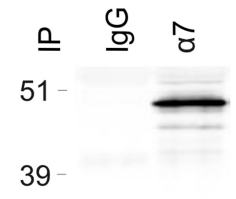

IB: anti-RIC-3

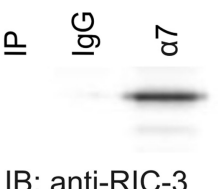

Figure 7. Role of RIC-3 in regulation of $\alpha 7$ expression. $\boldsymbol{A}$, Coexpression of mRIC-3 increased the total amount of $\alpha 7$. COS cells were transfected (TX) with human $\alpha 7 \mathrm{nAChR}$ CDNA alone or together with mRIC-3 cDNA. Cell lysates were analyzed by immunoblotting (IB) using a monoclonal antibody to $\alpha 7$, mAb319, which binds to both unfolded and folded $\alpha 7$ subunits. The result is representative of three independent experiments. $\boldsymbol{B}$, Detection of interaction between $\mathrm{mRIC}-3$ and $\alpha 7$ by coimmunoprecipitation. Lysates of cells overexpressing $\alpha 7$ and mRIC -3 were immunoprecipitated (IP) with either RIC-3 or $\alpha 7$ antibody and probed (IB) with $\alpha 7$ (left) or RIC-3 (right) antibody, respectively. Rabbit lgG and rat lgG were used as controls. To eliminate the possibility of nonspecific interactions, lysates of $\operatorname{COS}$ cells in which $\alpha 7$ and $\mathrm{mRIC}-3$ had been expressed separately were mixed. The immunoprecipitation performed on the mixture revealed no coprecipitation between the two proteins (data not shown). C, mRIC -3 binds unfolded $\alpha 7$. The lysates of $\operatorname{COS}$ cells overexpressing $\alpha 7$ and mRIC-3 were incubated with $\alpha$-BTX-conjugated agarose beads. The supernatants were precipitated with either RIC-3 or $\alpha 7$ antibody and probed with $\alpha 7$ (left) or RIC-3 (right) antibody, respectively.

$\alpha 7$ or anti-RIC-3 antibody (Fig. 7C). Assay of the cleared lysates confirmed that all toxin-binding activity had been removed by the agarose beads (data not shown). Together, these experiments show that RIC-3 binds to both unfolded (presumably unassembled) $\alpha 7$ subunits that do not bind toxin and also to folded and/or partially assembled subunits that remain in the ER.

In sum, these results suggest that mRIC-3 regulates the expression of $\alpha 7 \mathrm{nAChR}$ at multiple steps. It modestly elevates the expression of receptor subunits, but, more importantly, promotes both folding and oligomeric assembly, by binding to both unfolded subunits and to partially assembled receptors that have toxin-binding activity.

\section{The coiled-coil domain is essential for self-association of mRIC-3 but not for association with $\alpha 7$}

The importance of the highly conserved coiled-coil domain of mRIC-3 in $\alpha 7$ assembly, which has not been previously described, led us to investigate further its specific functional role. To assess the ability of mRIC-3(137-168) to form a coiled-coil, we synthesized a peptide corresponding to this region and tested whether it undergoes the concentration-dependent increase in $\alpha$-helical structure that is typical for coiled-coils. As can be seen from $C D$ spectra in Figure $8 A$, the peptide at low concentration $(5 \mu \mathrm{M})$ is predominantly unstructured, but becomes highly 
$\alpha$-helical at higher concentrations (270 $\mu \mathrm{M})$. This concentration-dependent conformational change of mRIC-3(137-168) is consistent with this sequence becoming a coiled-coil upon self-association.

In other proteins, the coiled-coil domain has been implicated in both intraand intermolecular protein-protein interactions (Burkhard et al., 2001). Because both mRIC- 3 and $\alpha 7$ are transmembrane proteins, we first hypothesized that interactions between the coiled-coil domain and the cytoplasmic portion of the $\alpha 7$ subunit mediate binding between the two proteins. Surprisingly, when $\alpha 7$ was coexpressed with either mRIC-3 or with mRIC-3( $\Delta 138-168)$, which has the coiled-coil domain deleted, similar levels of $\alpha 7$ were coprecipitated with both wildtype and mutant mRIC-3 (Fig. $8 \mathrm{~B}$ ), suggesting that deletion of the coiled-coil domain did not affect the interaction between mRIC-3 and $\alpha 7$. As a control, we also tested a mutant, mRIC-3(96-367) which has an $\mathrm{N}$-terminal truncation and is largely excluded from the ER (supplemental Fig. 1C, available at www.jneurosci.org as supplemental material). This protein failed to bind to the coexpressed receptor. We conclude that the coiled-coil domain is not required for the binding of mRIC-3 to $\alpha 7$.

The appearance of crystalloid ER in cells that overexpress mRIC-3 (Fig. $2 B$ ) suggested that mRIC-3 proteins might exhibit homotypic interactions. To test this idea, we examined lysates of cells transfected with both C-terminal myc-tagged and GFP-tagged mRIC-3. Western blot analysis indicated that both tagged proteins were expressed at similar levels (supplemental Fig. 3, available at www.jneurosci.org as supplemental material). Immunoprecipitation revealed a robust interaction between the tagged mRIC-3 proteins (Fig. $8 \mathrm{C}$ ). The shortest functional fragment mRIC-3(1168 ) also displayed a strong interaction. The interaction was significantly weaker, however, in mRIC-3(1-153), which only has the first half of the coiled-coil domain, and was not observed with a truncated mutant, mRIC-3(1-137), that terminates just before the coiled-coil domain. To determine whether the interaction is mediated solely by the coiled-coil domain, we examined mRIC-3 mutants with partial or complete coiled-coil domain deletions. Compared with the strong interaction observed between myctagged and GFP-tagged wild-type proteins, a significantly weaker interaction was observed in mRIC-3( $\Delta 154-168)$, which does not have the second half of the coiled-coil domain (Fig. $8 D$ ). Furthermore, no evidence of homotypic interaction was found for either mRIC-3( $\Delta 138-153)$, the mutant that lacks the first half of the coiled-coil domain, or for mRIC-3( $\Delta 138-168)$, in which the entire coiled-coil domain is deleted. The coiled-coil domain, which is essential for full functional activity of mRIC-3, is thus also required for self-association of mRIC-3, suggesting that mRIC-3 facilitates $\alpha 7$ assembly through association between its cytoplasmic coiled-coil domains.
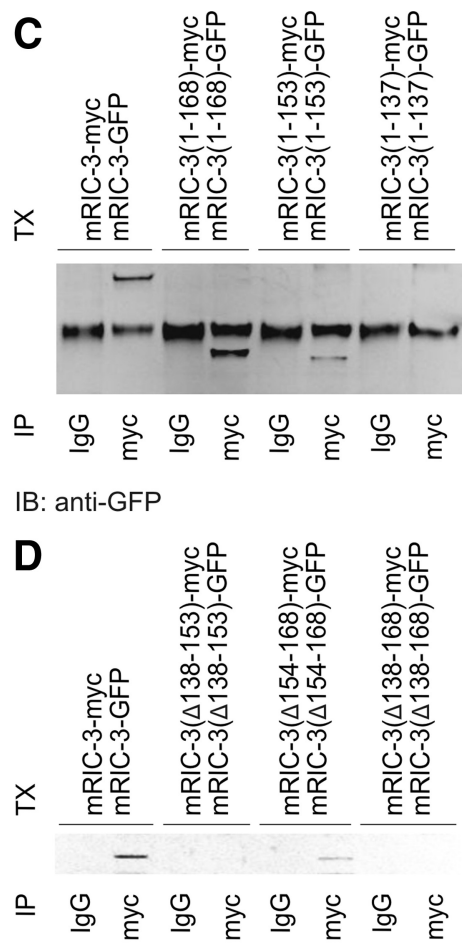

IB: anti-GFP

Figure 8. The coiled-coil domain is essential for self-association of mRIC-3. A, CD spectra of peptide corresponding to mRIC$3(137-168)$. Spectra were obtained at $25^{\circ} \mathrm{C}$ for peptide concentration of 5 and $270 \mu \mathrm{m}$. The sample at higher concentration gave rise to spectra with increased $\alpha$-helical content. $\boldsymbol{B}$, Lysates of cells expressing either wild-type or mutated mRIC-3 together with (ysantere immunoprecipitated with myc antibody and probed with anti-GFP antibody. Mouse lgG was used for controls. . antibody and probed with anti-GFP antibody. The myc-tagged and GFP-tagged mRIC-3( $\Delta 154-168)$ display weak interaction, while neither tagged mRIC-3( $\Delta 138-153)$ nor tagged mRIC-3( $\Delta 138-168)$ coprecipitate. TX, Transfection.

\section{Discussion}

In this report we have focused on four major unresolved questions with respect to mRIC-3: the role of the N-terminal sequence in targeting the protein to the ER; the transmembrane orientation of the protein; the role of RIC-3 in $\alpha 7$ subunit folding and assembly and the role of the coiled-coil domain.

Using colocalization with ER and Golgi markers as criteria, we find, in agreement with others (Halevi et al., 2002; Castillo et al., 2005; Cheng et al., 2007), that mRIC-3 in COS cells is localized almost exclusively to the ER. In contrast to the results of Cheng et al. (2007), who found evidence that RIC-3 cycles between the ER and Golgi, we observed that a mutated mRIC-3 protein that becomes glycosylated remains sensitive to Endo H (Fig. 5 C), suggesting that mRIC-3 is a resident ER protein that is not further processed in the Golgi.

mRIC- 3 is directed to the ER by the first 31 aa of the protein which function as a cleavable signal sequence. Thus, removal of these amino acids prevents efficient targeting to the ER, as does addition of GFP to the $\mathrm{N}$ terminus. In both cases, the altered mRIC-3 protein is diffusely distributed rather than being confined to the ER (Figs. 3Ab, 4A). For mRIC-3 and mRIC-3-GFP, but not for GFP-mRIC-3, expression in COS cells results in cleavage of the protein. Block of the N-terminal signal sequence is 

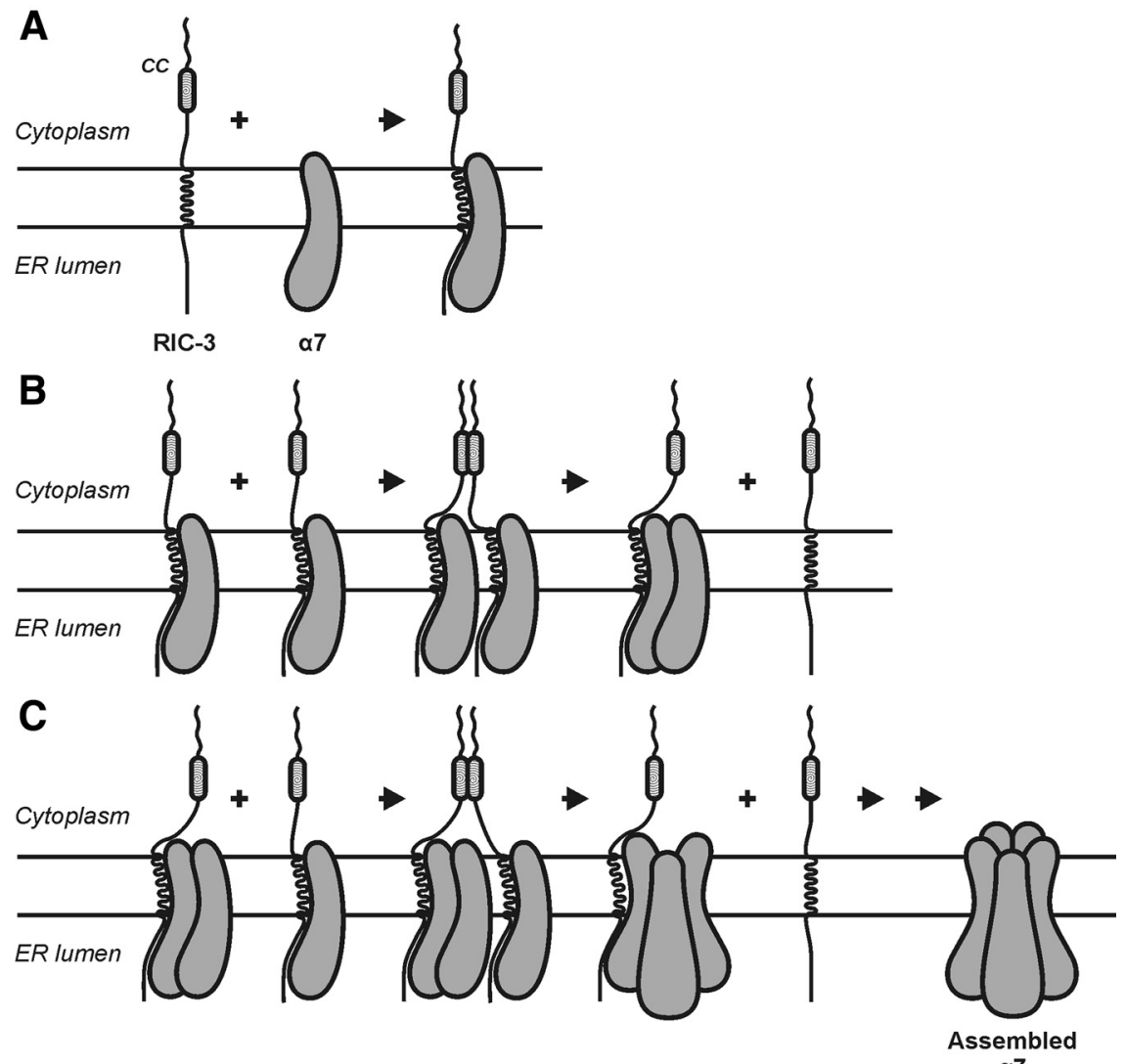

Figure 9. Model for the facilitation of $\alpha 7$ assembly by mRIC-3.A, mRIC -3 binds to the $\alpha 7$ monomer via interactions that do not involve the coiled-coil domain (CC). $B$, The self-association of mRIC-3 mediated by the coiled-coil domain brings the $\alpha 7$ monomer/ mRIC-3 complexes into close proximity and facilitates the dimerization of $\alpha 7$ monomers. Upon formation of the $\alpha 7$ dimer, one of the two RIC-3s is released. $C$, The $\alpha 7 \mathrm{dimer} / \mathrm{mRIC}-3$ complex is then free to associate with another $\alpha 7$ monomer bound to $\mathrm{mRIC}-3$. Iteration of this process results in the formation of a complete pentamer. In principle, this scheme is generally applicable to the mechanism of RIC-3 facilitation of both homopolymeric and heteropolymeric receptor assembly.

presumably responsible for the failure of GFP-mRIC-3 to be cleaved and for its altered cellular localization. In the native protein, amino acid analysis shows that cleavage occurs after amino acid 31. Finally, addition of the first 31 residues to a cytoplasmic protein, DsRed, causes it to be redirected to the ER (Fig. $4 B$ ). The $\mathrm{N}$-terminal sequence of $\mathrm{mRIC}-3$ thus functions as a signal sequence that is both necessary and sufficient for localization to the ER. These findings strongly support previous findings of Cheng et al. (2007), and are inconsistent with the findings in an in vitro translation system by Castelán et al. (2008).

To investigate the transmembrane orientation of mRIC-3, we examined whether consensus sequence sites for $N$-glycosylation, including both a single native site and several sites introduced into various positions of the protein, were glycosylated. We found that neither the native site, nor any site that was introduced on the C-terminal side of the putative transmembrane domain, was glycosylated. A site introduced on the N-terminal side of the hydrophobic sequence, in contrast, was glycosylated (Fig. 5). These results, combined with those showing a cleavable signal sequence, are consistent with the orientation of a single-pass type I membrane protein whose $\mathrm{N}$ terminal is lumenal.

Investigation of the functional domains of the protein, using both facilitation of expression of $\alpha 7$ in COS cells and inhibition of expression of a hybrid $5-\mathrm{HT}_{3} / \mathrm{AChR}$ receptor, indicates that the $\mathrm{N}$-terminal region, which is necessary for targeting to the ER, the lumenal domain, and the coiled-coil domain are all required for $\alpha 7$

full functional activity of mRIC-3. The C-terminal portion of the protein distal to the coiled-coil domain, in contrast, is dispensable (Fig. 6B; also see supplemental Fig. $2 A$, available at www.jneurosci.org as supplemental material). In the case of the $\alpha 7$ receptor, electrophysiological recording shows that surface toxin-binding activity corresponds to physiologically functional receptor (Fig. 6C; also see supplemental Fig. 2B, available at www. jneurosci.org as supplemental material).

The importance of the coiled-coil domain is a novel finding. Although the coiled-coil domain is highly conserved in all known RIC-3 family members, previous studies on other mammalian receptors have found that its deletion has no effect on the ability of RIC-3 to enhance (or depress) expression (Ben-Ami et al., 2005; Castillo et al., 2005; Cheng et al., 2007; Lansdell et al., 2008). Recent studies have shown that in C. elegans, a RIC-3 coiled-coil domain homologous to that in mRIC-3 is required for full expression of some, but not all, nAChRs (Biala et al., 2009). Biala et al. (2009) suggest that the coiled-coil domain might mediate the cell-type selection of specific nAChRs.

In comparison to the detailed physiological studies that have been made in $C$. elegans on the effects of RIC-3 mutations (Halevi et al., 2002), little information is available about the physiological role of the mammalian RIC-3 proteins. The variability of results in different expression systems suggests that other proteins may be involved. Such variability may explain the failure of previous studies to find a requirement of the coiled-coil domain in Drosophila and human RIC-3 proteins for $\alpha 7$ expression. Which of the effects seen in the heterologous systems is physiologically relevant must await in vivo mammalian studies.

We also investigated the role of RIC-3 in the pathway of $\alpha 7$ assembly and transport to the surface. In the absence of mRIC-3, $\alpha 7$ subunit is synthesized, but no receptor is detected on the surface, either by toxin-binding or electrophysiological assays. In addition, only a small amount (estimated to be $<15 \%$ ) of the $\alpha 7$ subunit shows $\alpha$-BTX binding activity, indicating that most of the subunit is unfolded and presumably unassembled. These observations suggest that RIC-3 must act before transport of the fully assembled receptor to the cell surface. Coexpression of mRIC-3 results in only a modest increase $(54 \pm 8 \%, n=3)$ in the total $\alpha 7$ subunit, but a very large increase $(\sim 10$-fold) in toxinbinding activity, suggesting that the primary role of mRIC-3 is to facilitate folding and assembly of the $\alpha 7$ subunit into pentameric receptors which are subsequently transported to the cell surface. Experiments with both muscle and neuronal nAChRs indicated that only fully assembled receptors are transported to the cell surface (Gu et al., 1991; Nicke et al., 2004). In addition to its effect on folding and assembly, mRIC-3 also appears to have an effect on $\alpha 7$ subunit synthesis, since in separate experiments (our unpublished observations), we found that RIC-3 does not increase 
$\alpha 7$ subunit degradation. Thus the increased amount of $\alpha 7$ seen with RIC-3 must be due to increased synthesis. Consistent with its role in facilitating $\alpha 7$ folding and assembly, we found that mRIC-3 binds to both unfolded subunits that do not bind toxin and to folded subunits that bind toxin. As previous studies have shown that toxin binds to partially assembled $\alpha 7$ receptors as well as to pentameric receptors (Sweileh et al., 2000), it is likely that mRIC-3 binds to partially assembled receptors in the ER. Previous studies have suggested in another system that RIC-3 binds to partially assembled receptors containing $\alpha 4$ and $\beta 2$ subunits (Lansdell et al., 2005).

We further investigated whether the coiled-coil domain plays a role in the association of mRIC-3 with $\alpha 7$ that we and others (Lansdell et al., 2005; Williams et al., 2005) have observed. We found that deletion of the coiled-coiled domain had no effect on the binding of mRIC- 3 to $\alpha 7$ (Fig. $8 \mathrm{~B}$ ). In contrast, we found that the coiled-coil domain is essential for the self-association of mRIC-3 (Fig. 8C,D), suggesting that RIC-3 self-association might play a role in facilitating assembly of the $\alpha 7$ receptor. As a model for further investigation (Fig. 9), we propose that unfolded $\alpha 7$ monomers associate with mRIC-3 in the ER to form a heterodimer via interactions that do not involve the coiled-coil domain (Fig. 9A). The self-association of the coiled-coiled domains of the mRIC-3 protein in the heterodimers may then bring the $\alpha 7$ monomers into close apposition and facilitate their dimerization (Fig. 9B). If one further supposes that $\alpha 7$ dimerization results in the release of one of the two associated mRIC-3 molecules, a similar set of interactions can result in the formation of a trimer, and, repeated in iterative manner, in the assembly of a complete pentamer (Fig. 9C). The proposed model is consistent with the observation that RIC-3 binds to both unfolded $\alpha 7$ subunits and to partially assembled $\alpha 7$ receptor. Whether toxin-binding is acquired as the result of folding of the $\alpha 7$ monomer, facilitated by RIC-3, or via association with other $\alpha 7$ subunits remains for future investigation.

During assembly of the mammalian muscle $\mathrm{nAChR}$, specific association between the subunits is achieved by interactions between the extracellular (lumenal) portions of the subunits ( $\mathrm{Yu}$ and Hall, 1991; Verrall and Hall, 1992; Wang et al., 1996b). One distinctive feature of the model proposed here is that the interactions between receptor subunits on the lumenal side of the ER membrane may be regulated and promoted by interactions between RIC-3, and perhaps other chaperone molecules, on the cytoplasmic side of the membrane. Because the specificity of the interactions is determined by the subunits, the model that we have suggested for RIC-3 facilitation of the assembly of a homopolymeric nAChR may also be applicable to the assembly of other, heteropolymeric receptors.

One intriguing observation is that the sequences C-terminal to the coiled-coil domain of RIC-3 appear to exert an inhibitory effect on RIC-3 function. Thus removal of this region led to a significant increase in the effect of RIC-3 on surface expression of $\alpha 7$ when compared with the full-length protein (Fig. $6 B, C$ ). The long C-terminal tail may regulate RIC-3 function by limiting the self-association of the protein, perhaps in interaction with other proteins. Interestingly, deletion of the $\mathrm{C}$ terminus of $\mathrm{mRIC}-3 \mathrm{did}$ not affect its suppression of $\alpha 7$ (V201)-5 $\mathrm{HT}_{3 \mathrm{~A}}$ expression (supplemental Fig. $2 \mathrm{~A}$, available at www.jneurosci.org as supplemental material). Further studies will be required to elucidate the details of $\mathrm{nAChR}$ assembly and its facilitation by chaperones in the ER.

\section{References}

Bachert C, Lee TH, Linstedt AD (2001) Lumenal endosomal and Golgiretrieval determinants involved in $\mathrm{pH}$-sensitive targeting of an early Golgi protein. Mol Biol Cell 12:3152-3160.

Bell P, Vandenberghe LH, Wu D, Johnston J, Limberis M, Wilson JM (2007) A comparative analysis of novel fluorescent proteins as reporters for gene transfer studies. J Histochem Cytochem 55:931-939.

Ben-Ami HC, Yassin L, Farah H, Michaeli A, Eshel M, Treinin M (2005) RIC-3 affects properties and quantity of nicotinic acetylcholine receptors via a mechanism that does not require the coiled-coil domains. J Biol Chem 280:28053-28060.

Biala Y, Liewald JF, Ben-Ami HC, Gottschalk A, Treinin M (2009) The conserved RIC-3 coiled-coil domain mediates receptor-specific interactions with nicotinic acetylcholine receptors. Mol Biol Cell 20:1419-1427.

Burkhard P, Stetefeld J, Strelkov SV (2001) Coiled coils: a highly versatile protein folding motif. Trends Cell Biol 11:82-88.

Castelán F, Castillo M, Mulet J, Sala S, Sala F, Domínguez Del Toro E, Criado M (2008) Molecular characterization and localization of the RIC-3 protein, an effector of nicotinic acetylcholine receptor expression. J Neurochem 105:617-627

Castillo M, Mulet J, Gutiérrez LM, Ortiz JA, Castelán F, Gerber S, Sala S, Sala F, Criado M (2005) Dual role of the RIC-3 protein in trafficking of serotonin and nicotinic acetylcholine receptors. J Biol Chem 280:27062-27068.

Chavez RA, Hall ZW (1991) The transmembrane topology of the amino terminus of the alpha subunit of the nicotinic acetylcholine receptor. J Biol Chem 266:15532-15538.

Cheng A, Bollan KA, Greenwood SM, Irving AJ, Connolly CN (2007) Differential subcellular localization of RIC-3 isoforms and their role in determining 5-HT3 receptor composition. J Biol Chem 282:26158-26166.

Dani JA, Bertrand D (2007) Nicotinic acetylcholine receptors and nicotinic cholinergic mechanisms of the central nervous system. Annu Rev Pharmacol Toxicol 47:699-729.

Eiselé JL, Bertrand S, Galzi JL, Devillers-Thiéry A, Changeux JP, Bertrand D (1993) Chimaeric nicotinic-serotonergic receptor combines distinct ligand binding and channel specificities. Nature 366:479-483.

Ferns M, Deiner M, Hall Z (1996) Agrin-induced acetylcholine receptor clustering in mammalian muscle requires tyrosine phosphorylation. J Cell Biol 132:937-944.

Forsayeth JR, Garcia PD (1994) Adenovirus-mediated transfection of cultured cells. Biotechniques 17:354-356:357-358.

Gee VJ, Kracun S, Cooper ST, Gibb AJ, Millar NS (2007) Identification of domains influencing assembly and ion channel properties in alpha 7 nicotinic receptor and 5-HT3 receptor subunit chimaeras. Br J Pharmacol 152:501-512.

Gething MJ (1999) Role and regulation of the ER chaperone BiP. Semin Cell Dev Biol 10:465-472.

Gu Y, Forsayeth JR, Verrall S, Yu XM, Hall ZW (1991) Assembly of the mammalian muscle acetylcholine receptor in transfected COS cells. J Cell Biol 114:799-807.

Halevi S, McKay J, Palfreyman M, Yassin L, Eshel M, Jorgensen E, Treinin M (2002) The C. elegans ric-3 gene is required for maturation of nicotinic acetylcholine receptors. EMBO J 21:1012-1020.

Halevi S, Yassin L, Eshel M, Sala F, Sala S, Criado M, Treinin M (2003) Conservation within the RIC-3 gene family. Effectors of mammalian nicotinic acetylcholine receptor expression. J Biol Chem 278:34411-34417.

Jayasinghe SA, Langen R (2005) Lipid membranes modulate the structure of islet amyloid polypeptide. Biochemistry 44:12113-12119.

Joyce JG, Hurni WM, Bogusky MJ, Garsky VM, Liang X, Citron MP, Danzeisen RC, Miller MD, Shiver JW, Keller PM (2002) Enhancement of alpha-helicity in the HIV-1 inhibitory peptide DP178 leads to an increased affinity for human monoclonal antibody 2F5 but does not elicit neutralizing responses in vitro. Implications for vaccine design. J Biol Chem 277:45811-45820.

Kornfeld R, Kornfeld S (1985) Assembly of asparagine-linked oligosaccharides. Annu Rev Biochem 54:631-664.

Lansdell SJ, Gee VJ, Harkness PC, Doward AI, Baker ER, Gibb AJ, Millar NS (2005) RIC-3 enhances functional expression of multiple nicotinic acetylcholine receptor subtypes in mammalian cells. Mol Pharmacol 68:1431-1438.

Lansdell SJ, Collins T, Yabe A, Gee VJ, Gibb AJ, Millar NS (2008) Host-cell specific effects of the nicotinic acetylcholine receptor chaperone RIC-3 
revealed by a comparison of human and Drosophila RIC-3 homologues. J Neurochem 105:1573-1581.

Lester HA, Dibas MI, Dahan DS, Leite JF, Dougherty DA (2004) Cys-loop receptors: new twists and turns. Trends Neurosci 27:329-336.

Li W, Keller GA, Haldar K (1995) Recognition of a $170 \mathrm{kD}$ protein in mammalian Golgi complexes by an antibody against malarial intraerythrocytic lamellae. Tissue Cell 27:355-367.

Linstedt AD, Mehta A, Suhan J, Reggio H, Hauri HP (1997) Sequence and overexpression of GPP130/GIMPc: evidence for saturable $\mathrm{pH}$-sensitive targeting of a type II early Golgi membrane protein. Mol Biol Cell 8:1073-1087.

Luz JM, Lennarz WJ (1996) Protein disulfide isomerase: a multifunctional protein of the endoplasmic reticulum. EXS 77:97-117.

McGehee DS (1999) Molecular diversity of neuronal nicotinic acetylcholine receptors. Ann N Y Acad Sci 868:565-577.

McGehee DS, Role LW (1995) Physiological diversity of nicotinic acetylcholine receptors expressed by vertebrate neurons. Annu Rev Physiol 57:521-546.

Millar NS (2003) Assembly and subunit diversity of nicotinic acetylcholine receptors. Biochem Soc Trans 31:869-874.

Millar NS (2008) RIC-3: a nicotinic acetylcholine receptor chaperone. Br J Pharmacol 153 [Suppl 1]:S177-S183.

Miller KG, Alfonso A, Nguyen M, Crowell JA, Johnson CD, Rand JB (1996) A genetic selection for Caenorhabditis elegans synaptic transmission mutants. Proc Natl Acad Sci U S A 93:12593-12598.

Nicke A, Thurau H, Sadtler S, Rettinger J, Schmalzing G (2004) Assembly of nicotinic alpha7 subunits in Xenopus oocytes is partially blocked at the tetramer level. FEBS Lett 575:52-58.

Plummer TH Jr, Tarentino AL (1991) Purification of the oligosaccharidecleaving enzymes of Flavobacterium meningosepticum. Glycobiology 1:257-263.

Puri S, Bachert C, Fimmel CJ, Linstedt AD (2002) Cycling of early Golgi proteins via the cell surface and endosomes upon lumenal $\mathrm{pH}$ disruption. Traffic 3:641-653.

Sanes JR, Lichtman JW (2001) Induction, assembly, maturation and maintenance of a postsynaptic apparatus. Nat Rev Neurosci 2:791-805.
Snapp EL, Hegde RS, Francolini M, Lombardo F, Colombo S, Pedrazzini E, Borgese N, Lippincott-Schwartz J (2003) Formation of stacked ER cisternae by low affinity protein interactions. J Cell Biol 163:257-269.

Spellman MW (1990) Carbohydrate characterization of recombinant glycoproteins of pharmaceutical interest. Anal Chem 62:1714-1722.

Sweileh W, Wenberg K, Xu J, Forsayeth J, Hardy S, Loring RH (2000) Multistep expression and assembly of neuronal nicotinic receptors is both host-cell- and receptor-subtype-dependent. Brain Res Mol Brain Res 75:293-302.

Verrall S, Hall ZW (1992) The N-terminal domains of acetylcholine receptor subunits contain recognition signals for the initial steps of receptor assembly. Cell 68:23-31.

Virtanen I, Ekblom P, Laurila P (1980) Subcellular compartmentalization of saccharide moieties in cultured normal and malignant cells. J Cell Biol 85:429-434.

Wang ZZ, Hardy SF, Hall ZW (1996a) Membrane tethering enables an extracellular domain of the acetylcholine receptor alpha subunit to form a heterodimeric ligand-binding site. J Cell Biol 135:809-817.

Wang ZZ, Hardy SF, Hall ZW (1996b) Assembly of the nicotinic acetylcholine receptor. The first transmembrane domains of truncated alpha and delta subunits are required for heterodimer formation in vivo. J Biol Chem 271:27575-27584.

Williams ME, Burton B, Urrutia A, Shcherbatko A, Chavez-Noriega LE, Cohen CJ, Aiyar J (2005) Ric-3 promotes functional expression of the nicotinic acetylcholine receptor alpha7 subunit in mammalian cells. J Biol Chem 280:1257-1263.

Yamamoto A, Masaki R, Tashiro Y (1996) Formation of crystalloid endoplasmic reticulum in COS cells upon overexpression of microsomal aldehyde dehydrogenase by cDNA transfection. J Cell Sci 109:1727-1738.

Yu XM, Hall ZW (1991) Extracellular domains mediating epsilon subunit interactions of muscle acetylcholine receptor. Nature 352:64-67.

Yu XM, Hall ZW (1994) Amino- and carboxyl-terminal domains specify the identity of the delta subunit in assembly of the mouse muscle nicotinic acetylcholine receptor. Mol Pharmacol 46:964-969. 